\title{
SCIENTIFIC REP RTS OPEN Author Correction: Lack of acclimatization to chronic hypoxia in humans in the Antarctica
}

Simone Porcelli ${ }^{1}{ }^{1}$, Mauro Marzorati ${ }^{1}{ }^{1}$, Beth Healey ${ }^{2}$, Laura Terraneo ${ }^{3}$, Alessandra Vezzoli ${ }^{1}$, Silvia Della Bella ${ }^{4,6}$, Roberto Dicasillati ${ }^{5}$ \& Michele Samaja ${ }^{3}$

Correction to: Scientific Reports https://doi.org/10.1038/s41598-017-18212-1, published online 22 December 2017

The original version of this Article omitted an affiliation for Silvia Della Bella. The correct affiliations are listed below:

Department of Medical Biotechnologies and Translational Medicine, University of Milan, Milan, (MI), Italy.

Unit of Clinical and Experimental Immunology, Humanitas Clinical and Research Center, Rozzano, Milan, Italy.

This has now been corrected in the HTML and PDF versions of this Article.

(c) (i) Open Access This article is licensed under a Creative Commons Attribution 4.0 International Ly License, which permits use, sharing, adaptation, distribution and reproduction in any medium or format, as long as you give appropriate credit to the original author(s) and the source, provide a link to the Creative Commons license, and indicate if changes were made. The images or other third party material in this article are included in the article's Creative Commons license, unless indicated otherwise in a credit line to the material. If material is not included in the article's Creative Commons license and your intended use is not permitted by statutory regulation or exceeds the permitted use, you will need to obtain permission directly from the copyright holder. To view a copy of this license, visit http://creativecommons.org/licenses/by/4.0/.

(c) The Author(s) 2018

${ }^{1}$ Institute of Molecular Bioimaging and Physiology, National Research Council, Segrate, (MI), Italy. ${ }^{2}$ Biomedical Research, European Space Agency, Concordia, Antarctica. ${ }^{3}$ Department of Health Science, University of Milan, Milan, (MI), Italy. ${ }^{4}$ Department of Medical Biotechnologies and Translational Medicine, University of Milan, Milan, (MI), Italy. ${ }^{5}$ ASST Santi Paolo e Carlo, Milan, (MI), Italy. ${ }^{6}$ Unit of Clinical and Experimental Immunology, Humanitas Clinical and Research Center, Rozzano, Milan, Italy. Correspondence and requests for materials should be addressed to M.M. (email: mauro.marzorati@ibfm.cnr.it) 